\title{
Proteasome Involvement and Accumulation of Ubiquitinated Proteins in Cerebellar Granule Neurons Undergoing Apoptosis
}

\author{
Nadia Canu, ${ }^{1}$ Christian Barbato, ${ }^{1}$ Maria Teresa Ciotti, ${ }^{2}$ Annalucia Serafino, ${ }^{3}$ Laura Dus, ${ }^{2}$ and \\ Pietro Calissano ${ }^{1,2}$ \\ ${ }^{1}$ Dipartimento di Neuroscienze, Facoltà di Medicina e Chirurgia, Università di Tor Vergata, 00133 Roma, Italia, 2/stituto di \\ Neurobiologia, Consiglio Nazionale delle Ricerche (CNR), 00137 Roma, Italia, and ${ }^{3}$ Area di Ricerca di Roma, Tor Vergata, \\ CNR, 00133 Roma, Italia
}

\begin{abstract}
We investigated the potential role of the ubiquitin proteolytic system in the death of cerebellar granule neurons induced by reduction of extracellular potassium. Inhibitors of proteasomal function block apoptosis if administered at onset of this process, but they do not exert such effect when added 2-3 hr later. The same inhibitors also prevent caspase- 3 activity and calpain-caspase-3-mediated processing of tau protein, suggesting that proteasomes are involved upstream of the caspase activation. Although the proteasomes seem to play an early primary role in programmed cell death, we found that with progression of apoptosis, during the execution phase, a perturbation in normal ubiquitin-proteasome function occurs, and high levels of ubiquitinated proteins accumulate in the cytoplasm of dying cells. Such accumulation correlates with a
\end{abstract}

The presence of intracellular inclusions of insoluble aggregates of ubiquitin protein conjugates is a hallmark of chronic neurodegenerative diseases and, to lesser extent, of physiological brain aging (Lowe et al., 1993). To date, the mechanism or mechanisms leading to such aberrant deposits is unknown. Over time, the accumulation of ubiquitinated proteins results in pathological aggregates that perturb the normal physiology of affected neurons and lead to proteotoxicity.

Ubiquitination of proteins is required for rapid degradation of short-lived or of damaged proteins by the ubiquitin-proteasome system. This is the major proteolytic system in the cytosol of eukaryotic cells endowed with multiple activities, referred to as chymotrypsin-like, trypsin-like, and postacidic or caspase-like activities (Peters, 1994).

In the ubiquitin-proteasome pathway, proteins are first modified by the covalent conjugation to multiple ubiquitin molecules that subsequently tag the conjugates for rapid hydrolysis by the proteasome. This complex hydrolyzes exhaustively target proteins releasing small peptides, most of which are further degraded by cellular exopeptidases, with concomitant recycling of ubiquitin molecules by deubiquitinating enzymes (Wilkinson, 1997).

Received June 25, 1999; revised Oct. 29, 1999; accepted Nov. 3, 1999.

This work was supported by Telethon-Italy (Grant E855), Progetto Finalizzato Biotecnologie, and Cofinanziamento Ministero dell'Universitá e della Ricerca Scientifica e Tecnologica (40\% to P.C.). We thank Dr. Andrea Levi for comments on this manuscript and Marianna De Bernardinis for helpful suggestions on MTT assay.

Correspondence should be addressed to Dr. Nadia Canu, Istituto di Neurobiologia Consiglio Nazionale delle Ricerche, V.le Marx 15, 00137 Roma, Italia. E-mail: nadia@biocell.irmkant.rm.cnr.it.

Copyright (C) 2000 Society for Neuroscience $\quad 0270-6474 / 00 / 200589-11 \$ 15.00 / 0$ progressive decline of proteasome chymotrypsin and trypsinlike activities and, to a lower extent, of postacidic-like activity. Both intracytoplasmic accumulation of ubiquitinated proteins and decline of proteasome function are reversed by the pancaspase inhibitor Z-VAD-fmk. The decline in proteasome function is accompanied by, and likely attributable to, a marked and progressive decline of deubiquitinating activities. The finding that the proteasomes are early involved in apoptosis and that ubiquitinated proteins accumulate during this process prospect granule neurons as a model system aimed at correlating these events with neurodegenerative diseases.

Key words: apoptosis; neurodegeneration; ubiquitin-protein conjugates; proteasome activity; deubiquitinating activity; cerebellar granule neurons

A growing number of studies indicate that ubiquitin-mediated proteolysis plays important roles in a variety of basic cellular processes such as regulation of cell cycle and division, response to cellular stress, morphogenesis of neuronal network, long-term synaptic plasticity, transcriptional regulation of cell surface receptors (Jentsch 1992; Ciechanover 1994; Hochstrasser 1995), and activation of the transcription factor NF-KB (Palombella et al., 1995). Moreover, several observations suggest that a perturbation in ubiquitin-proteasome function plays a critical role in the accumulation of misfolded or modified proteins such as paired helical filaments in Alzheimer's disease (Morishima-Kawashima et al., 1993), nuclear aggregates of huntingtin in Huntington's disease (DiFiglia et al., 1997), and aggregation of $\alpha$-synuclein in Parkinson's disease (Takeda et al., 1998). The inability of removing ubiquitin conjugates may result from an altered proteolytic degradation or from a modification of damaged proteins that makes them inaccessible to proteolytic machinery.

It has been recently reported that the proteasome system is critically involved in programmed cell death, by acting upstream of caspase activation. Generally, proliferating cells respond to inhibitors of proteasome function by activation of apoptosis, whereas in nondividing cells (sympathetic neurons or T-cells) such inhibitors exert antiapoptotic effects (Grimm et al., 1996; Sadoul et al., 1996; Drexler, 1997). On the other hand, it has been postulated that apoptosis plays a role in the pathogenesis of neurodegenerative diseases ( $\mathrm{Su}$ et al., 1994; Smale et al., 1995; Thompson, 1995).

In view of the postulated connection of apoptotic death, altered proteasome function, and neurodegenerative diseases, we investigated the role of ubiquitin-proteasome system in an in vitro 
model of cerebellar granule cells (CGCs) undergoing massive apoptotic death after removal of depolarizing concentration of potassium (D'Mello et al., 1993). We report that the proteasome system appears twice involved during apoptosis: first, its function is crucial in the early phase, upstream caspase activation, then, in the execution phase, proteasome function declines with consequent accumulation of ubiquitinated proteins. Moreover, an impairment of deubiquitinating activities accompanies and likely contributes to the proteasome failure.

\section{MATERIALS AND METHODS}

The proteasome inhibitors PSI [Z-Ile-Glu (OtBu)-Ala-Leucinal] and Lactacystin and the caspase inhibitor z-VAD-fmk (BenzyloxycarbonylVal-Ala-Asp-fluoromethylchetone) were from Calbiochem (La Jolla, CA). The proteasome inhibitor MG132 (N-CBZ-Leu-Leu-Leu-Al), the calpain inhibitor II ALLM ( $N$-acetyl-Leu-Leu-Methioninal), E64d (trans-epoxy succinyl-L-leucylamydo-3-methyl-butane ethyl ester), and leupeptin were purchased from Sigma (St. Louis, MO). Substances were dissolved in dimethylsulfoxide at $1000 \times$ concentration. No more than $0.1 \%$ solvent was present in culture medium. The fluorogenic substrates for proteasome assay Suc-LLVY-MCA (succinyl-Leu-Leu-Val-Tyr-7amido-4-methylcoumarin), Boc-LRR-MCA (N-t-boc-Leu-Arg-Arg-7amido-4-methylcoumarin), and Z-LLE- $\beta$ Nap (N-CBZ-Leu-Leu-Glu- $\beta$ naphtylamide) were from Sigma. Multi-ubiquitin chains [Ub4, Ub3 and $\mathrm{Ub} 2$, and the monoclonal antibody (mAb) to $\alpha$-type subunits (PW8195)] were from AFFINITI Research Products Ltd. Ac-DEVD-AMC was from Biomol (Plymouth Meeting, PA). Rabbit anti-ubiquitin was from Dako (Carpinteria, CA).

Neuronal cultures. Cultures enriched in granule neurons were obtained from dissociated cerebella of 8-d-old Wistar rats (Charles River, Calco, Italy), as described by Levi et al. (1984). Cells were plated in basal medium Eagle (BME; Life Technologies, Gaithersburg, MD) supplemented with $10 \%$ fetal bovine serum, $25 \mathrm{~mm} \mathrm{KCl}$, and $2 \mathrm{~mm}$ glutamine (Life Technologies) on dishes (Nunc, Roskilde, Denmark) coated with poly-L-lysine. Cells were plated at $2.5 \times 10^{6}$ per $35 \mathrm{~mm}$ dish or $7 \times 10^{6}$ per $60 \mathrm{~mm}$ dish. $1 \beta$-Arabinof uranosylcytosine $(10 \mathrm{~mm})$ was added to the culture medium $18-22 \mathrm{hr}$ after plating to prevent proliferation of nonneuronal cells.

Induction of apoptosis. Cultures at 6-7 days in vitro (DIV) were washed two times and switched in serum-free BME containing $5 \mathrm{mM} \mathrm{KCl}$ supplemented with glutamine and gentamicin. Control cells were washed with $\mathrm{BME}$ and maintained in serum-free medium containing $25 \mathrm{mM} \mathrm{KCl}$ (D'Mello et al., 1993).

Assessment of neuronal viability. Viable granule neurons were quantified by counting the number of intact nuclei after lysing the cells in detergent-containing solution by the method of Soto and Sonnenschein (1985) modified by Volontè et al. (1994) and by the MTT tetrazolium salt assay, as described by Manthorpe et al. (1986). Briefly, MTT tetrazolium salt $(0.25 \mathrm{mg} / \mathrm{ml})$ was added to neurons grown in 24-well plates and incubated for $1-2 \mathrm{hr}$ at $37^{\circ} \mathrm{C}$. The reaction media were then gently aspirated, and isopropanol containing $0.08 \mathrm{~N} \mathrm{HCl}$ was added to solubilize the blue formazan product. Formazan-isopranol mixtures were then transferred to 96-well plates and quantified using a Multiskan plate reader at $570 \mathrm{~nm}$ (Labsystems Multiskan MCC/340).

Immuofluorescence. Cerebellar granule cells were fixed with $4 \%$ paraformaldehyde ( $\mathrm{w} / \mathrm{v}$ in PBS) for $15 \mathrm{~min}$ at room temperature, washed in PBS, $\mathrm{pH} 7.5$, and then permeabilized with $0.1 \%$ Triton X-100 and Tris$\mathrm{Cl}$, pH 7.5, for $5 \mathrm{~min}$. The coverslips were treated with polyclonal antibody against ubiquitin (Dako; 1:100) in a moist chamber overnight at $4^{\circ} \mathrm{C}$, rinsed in PBS, and stained with FITC-conjugated secondary antibodies (Sigma) for $30 \mathrm{~min}$. Nuclei were stained with propidium iodide (Sigma; $5 \mu \mathrm{g} / \mathrm{ml})$ and RNase $(100 \mu \mathrm{g} / \mathrm{ml})$ in PBS for $5 \mathrm{~min}$ at room temperature. Confocal microscopy was performed with a Leica (Nussloch, Germany) TCS 4D system, equipped with $100 \times 1.3-0.6$ oilimmersion objective (optical section, $1 \mu \mathrm{M}$ ). Images of double-labeled samples were recorded with simultaneous excitation and detection of both dyes to ensure proper image alignment. Optical sections were stereo-pair and three-dimensional reconstituted. To correct for possible crosstalk resulting from overlapping excitation and emission spectra of the dyes used, when necessary, recorded images were corrected using the MultiColor analysis package software by Leica.

Caspase-3 activity: DEVD-MCA cleavage assay. DEVD-MCA cleavage activity was measured, as described by Armstrong et al. (1997). After $12 \mathrm{hr}$ in S-K5, 500,000 granule cells were washed once with PBS and lysed in 100 $\mu l$ of buffer A (10 mm HEPES, $\mathrm{pH} 7.4,42 \mathrm{~mm} \mathrm{KCl}, 5 \mathrm{~mm} \mathrm{MgCl}_{2}, 1 \mathrm{~mm}$ DTT, and $1 \mathrm{~mm}$ PMSF, 0.5\% 3-[(3-cholamidopropyl)dimethylammonio]-1propanesulfonic acid (CHAPS), and $1 \mu \mathrm{g} / \mathrm{ml}$ leupeptin). Twenty-five microliters of lysate was combined with $75 \mu \mathrm{l}$ of buffer B (25 mM HEPES, $1 \mathrm{~mm}$ EDTA, $0.1 \%$ CHAPS, $10 \%$ sucrose, and 3 mM DTT, pH 7.5) containing 30 $\mu \mathrm{M}$ Ac-DEVD-AMC and incubated for $20 \mathrm{~min}$ at room temperature. Fluorescence was measured at an excitation of $380 \mathrm{~nm}$ and an emission of $460 \mathrm{~nm}$ using a Kontron AG (Zurich, Switzerland) SFM spectrofluorometer.

Fluorogenic peptide substrate assay for proteasome activity. CGCs were lysed in ice-cold homogenization buffer [ $20 \mathrm{~mm}$ Tris/ HCl, $\mathrm{pH} 7.2,0.1 \mathrm{~mm}$ EDTA, $1 \mathrm{~mm}$ 2-mercaptoethanol, $5 \mathrm{~mm}$ ATP, $20 \%$ (v/v) glycerol, and $0.04 \%$ (v/v) Nonidet P-40, as described in Beyette et al. (1998)]. Lysates $(10 \mu \mathrm{g})$ of CGCs were incubated at $37^{\circ} \mathrm{C}$ with the fluorogenic substrates Suc-LLVY-MCA $(50 \mu \mathrm{M})$, Boc-LRR-MCA $(100 \mu \mathrm{M})$, and Z-LLE- $\beta$ Nap $(400 \mu \mathrm{M})$ in $100 \mu \mathrm{l}$ of $50 \mathrm{~mm}$ HEPES, pH 8, 5 mM EGTA, for 20, 30, and $60 \mathrm{~min}$, respectively. The reaction was stopped by adding $900 \mu \mathrm{l}$ of SDS (1\%). Hydrolysis of peptides was measured at $380 \mathrm{~nm}$ excitation and 460 emission for MCA and at $335 \mathrm{~nm}$ excitation and $410 \mathrm{~nm}$ emission for $\beta$ Nap using a Kontron SFM spectrofluorometer.

Western blot analysis. Equal amounts of proteins were subjected to SDS-PAGE on $8-15 \%$ linear gradient gels (Laemmli, 1970). After electroblotting to nitrocellulose (Hybond-C), proteins were visualized using appropriate primary antibodies. All primary antibodies were diluted in $0.5 \%(\mathrm{w} / \mathrm{v})$ nonfat dry milk and incubated with the nitrocellulose blot overnight at $4^{\circ} \mathrm{C}$. Incubation with secondary peroxidase-coupled antimouse or anti-rabbit antibodies was performed at room temperature for $45 \mathrm{~min}$. Blots were developed by using the ECL system (Amersham, Arlington Heights, IL). Developments of Western blots were terminated before band intensity was saturated; relative optical densities and areas of bands were quantified using a computerized image analysis system.

Preparation of protein extracts from CGCs and assay for deubiquitinating activity. CGCs were collected and resuspended in ice-cold lysis buffer (20 mm Tris- $\mathrm{HCl}, \mathrm{pH} 7.2,10 \mathrm{~mm} \mathrm{MgCl} 2,1 \mathrm{~mm}$ EDTA, 5\% glycerol, $1 \mathrm{~mm}$ DTT, $1 \mu \mathrm{g} / \mathrm{ml}$ aprotinin, and $1 \mu \mathrm{g} / \mathrm{ml}$ pepstatin) and frozen and thawed three times. The extracts were centrif uged, and supernatants were stored at $-70^{\circ} \mathrm{C}$ as $50 \%$ glycerol solutions. Assay of deubiquitinating enzyme (DUB) activity was conducted at $22^{\circ} \mathrm{C}$ in a buffer containing $50 \mathrm{~mm}$ Tris- $\mathrm{HCl}, \mathrm{pH} 7.3$, and $5 \mathrm{~mm}$ DTT in a total volume of $30 \mu \mathrm{l}$. Reaction mixture contained $5 \mu \mathrm{g}$ of CGC extract and $1 \mu \mathrm{g}$ of multi-ubiquitin chains. Aliquots of $5 \mu \mathrm{l}$ were removed and separated by $12.5 \%$ polyacrylamide gels, using a Tricine gel system (Schagger and von Jagow, 1987), transferred to Immobilon P membranes (Millipore, Bedford, MA) and analyzed by anti-ubiquitin antibody.

\section{RESULTS}

\section{Inhibition of proteasome function rescues granule neurons from $\mathrm{K}^{+}$deprivation-induced cell death}

Rat cerebellar granule neurons can be induced to undergo apoptosis if the potassium concentration is reduced to $5 \mathrm{~mm}(\mathrm{~K} 5)$ and serum is removed $(\mathrm{S}-)$ after a period of initial growth in $25 \mathrm{~mm}$ potassium (K25) and serum (S+) (D’Mello et al., 1993; Galli et al., 1995). Commitment to apoptosis occurs between 2 and $6 \mathrm{hr}$ after $\mathrm{K}^{+}$deprivation (Galli et al., 1995; Schulz et al., 1996; Nardi et al., 1997) and at 6-8 hr degenerative changes such as chromatin condensation, vacuole formation, DNA fragmentation, and neurite retraction become detectable (D'Mello et al., 1993; Schulz et al., 1996; Armstrong et al., 1997). Moreover, during the same period the microtubule-associated protein tau is being degraded by caspase- 3 and calpain to a $17 \mathrm{kDa}$ fragment that accumulates in perikarya of dying neurons (Canu et al., 1998), and an amyloidogenic route leading to an increased secretion of $\beta$-amyloid is activated (Galli et al., 1998).

Because the proteasome system has been implicated as a positive mediator of apoptosis triggered by damaging stimuli in terminally differentiated cell types e.g., by degrading regulatory proteins that normally inhibit the apoptotic pathway or activating proteins that promote cell death likely working upstream the caspase-activation (Grimm et al., 1996; Sadoul et al., 1996), we investigated the involvement of proteasome system in the CGC 
model of neuronal apoptosis. To this aim the effects of a panel of proteasome inhibitors on the survival of CGCs were examined. The peptide aldehydes MG132 and PSI [Z-IE(OtBu)AL-CHO] have been shown to reversibly inhibit the proteolytic activity of proteasomes (Figueiredo-Pereira et al., 1994; Rock et al., 1994), whereas Lactacystin, a microbial metabolite, irreversibly blocks the proteasome function (Fenteany et al., 1995). These substances were added before or simultaneously with the induction of apoptosis, and neuronal survival was assessed $12 \mathrm{hr}$ later because at longer incubation times these inhibitors become toxic. Cell viability was analyzed by counting the number of intact nuclei and by the MTT assay, as described in Materials and Methods. Results shown in Figure 1, $A$ and $B$, provide evidence that MG132 and Lactacystin significantly inhibit apoptosis. MG132 was a more potent inhibitor of cell death, producing $>90 \%$ inhibition of cell death at $2 \mu \mathrm{M}$ as compared with Lactacystin, which inhibits cell death by $85 \%$ at $25 \mu \mathrm{M}$. In the presence of these compounds, the cell bodies of neurons and the neurites remained intact for 12-18 hr (data not shown). By contrast, PSI protects CGCs from apoptosis only partially (20\%) and at 50-100 $\mu \mathrm{M}$ as assessed by counting the number of intact nuclei. Very similar results are obtained when viability is assayed with the MTT procedure (Fig. $1 B$ ) with a slight difference at high concentration of PSI $(50 \mu \mathrm{M})$, indicating that the mitochondrial function is still partially operative in a portion of neurons. Because MG132 also affects calpain and cathepsin besides proteasomes, we also tested the effect of ALLM $(5-50 \mu \mathrm{M})$, E64d ester $(20-100 \mu \mathrm{M})$, and leupeptin $(20-100 \mu \mathrm{M})$, which are cell-permeable inhibitors of calpain and cathepsin. As indicated in Figure $1 C$, these agents failed to rescue CGCs from apoptosis, suggesting that MG132 elicits its effects by acting primarily on proteasomes.

We found that MG132 must be added within $1 \mathrm{hr}$ after induction to efficiently block apoptosis (Fig. 2), whereas no rescuing effect was noticed when this agent was given $3 \mathrm{hr}$ after the apoptotic stimulus. Identical results were obtained with Lactacystin (data not shown). This finding supports the hypothesis that proteasome inhibitors act on the early events of apoptosis (Grimm et al., 1996; Sadoul et al., 1996) and become ineffective after the commitment point that occurs between 2-6 hr after apoptotic stimulus (Galli et al., 1995; Schulz et al., 1996; Nardi et al., 1997).

\section{Inhibition of proteasome function prevents caspase-3 activity and cleavage of the microtubule-associated protein tau}

The execution phase of apoptosis is initiated by activation of specific proteases of the caspase family (Steller, 1995). Of the caspases, caspase-3 is that involved in the cleavage of most apoptotic substrates (Cohen, 1997). An increase of caspase-3 activity is also present in extracts of granule neurons undergoing apoptosis (Eldadah et al., 1997; Marks et al., 1998; Bobba et al., 1999). We investigated the role of proteasome with respect to this protease activity. Primary CGCs were induced to die in the absence or in the presence of MG132 (5 $\mu \mathrm{M})$, Lactacystin (25 $\mu \mathrm{M})$, and PSI $(20$ and $50 \mu \mathrm{M})$. Twelve hours later caspase-3 activity was assayed by the cleavage of the fluorogenic substrate Ac-DEVD-MCA (Enari et al., 1996). As shown in Figure 3A, neurons undergoing apoptosis exhibited a 12- to 13-fold elevation of caspase- 3 activity as compared to controls. Caspase activation induced by apoptosis is partially inhibited by MG132, Lactacystin, and PSI to an extent which, at least in part, mirrors their anti-apoptotic effect. To date, only few intracellular substrates of
(A)

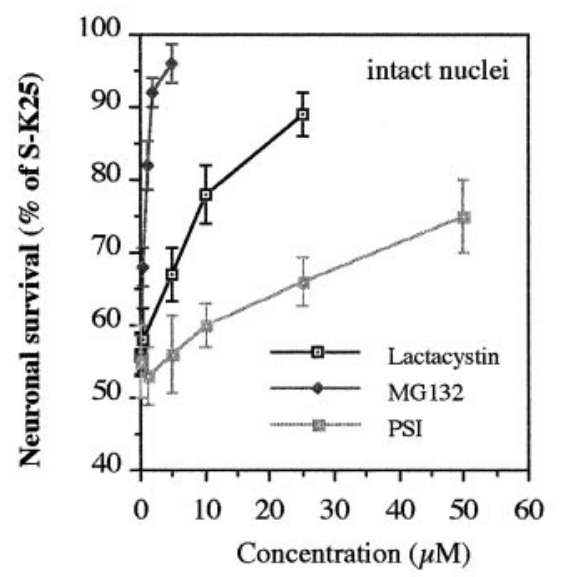

(B)

(C)
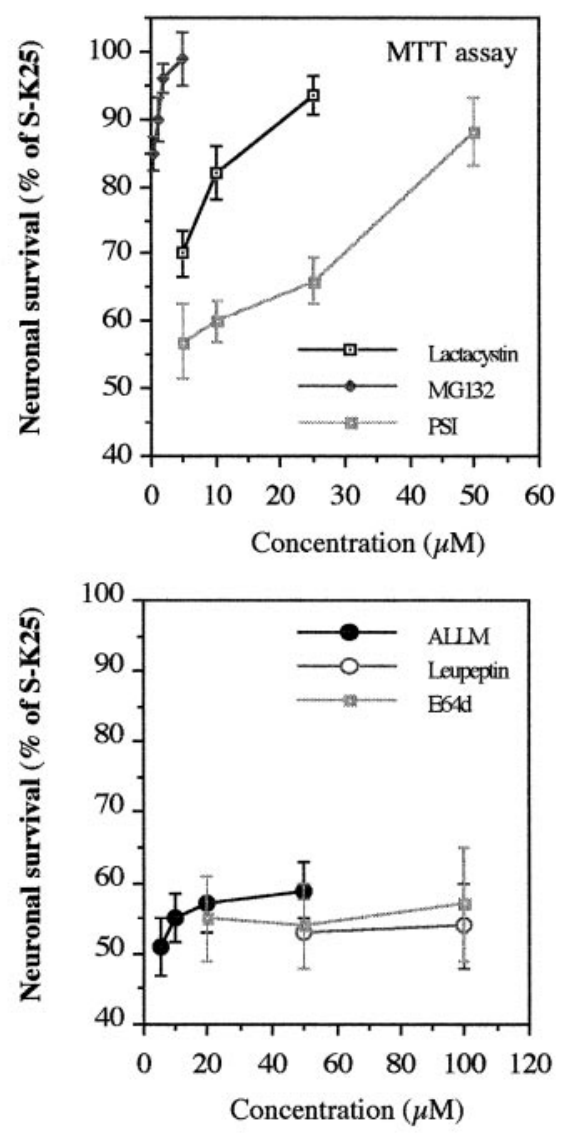

Figure 1. Inhibitors of proteasome rescue cerebellar neurons from apoptosis. Cultures at 6 DIV were washed and maintained in high-potassium and serum-free medium (S-K25) or switched to K5 and serum-free medium (S-K5) in the absence or in the presence of different concentrations of proteasome inhibitors. After $12 \mathrm{hr}$, cell viability was determined by counting the number of intact nuclei $(A)$ or by MTT assay $(B)$, as described in Materials and Methods. $C$, Effect of calpain and cathepsin inhibitors on cell survival. ALLM, E64d, and leupeptin were added to the medium at the concentrations indicated. Twelve to $15 \mathrm{hr}$ after apoptosis induction, granule neurons were analyzed for survival, as described in Materials and Methods. Results are means \pm SD of duplicate determinations of three independent experiments.

activated caspase-3 have been identified in CGCs undergoing apoptosis (Nath et al., 1996; Canu et al., 1998). For instance we have reported that in CGCs undergoing apoptosis the microtubule-associated protein tau is a substrate for both 


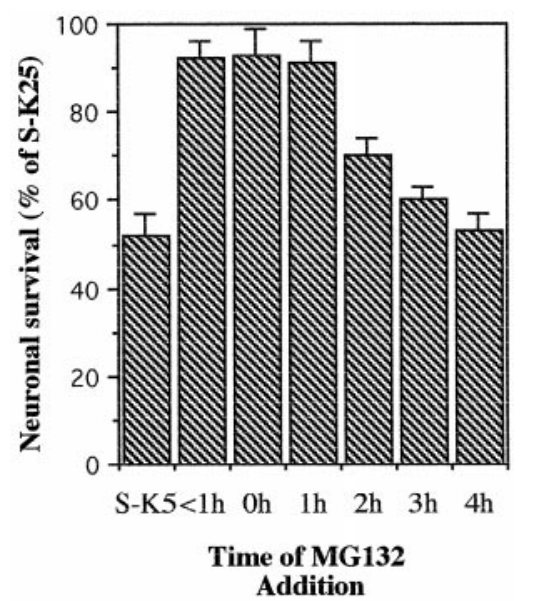

Figure 2. Rescue time by MG132 on granule neurons undergoing apoptosis. Cells were exposed to $5 \mu \mathrm{M}$ MG132 either $1 \mathrm{hr}$ before $(<1 \mathrm{hr})$ or at different times after apoptotic stimulus. The number of viable cells was determined $12 \mathrm{hr}$ later, as described in Materials and Methods.

caspase- 3 and calpain with a production of a diagnostic fragment of $17 \mathrm{kDa}$ and concomitant collapse of the microtubule network (Canu et al., 1998). Whole-cell extracts prepared from CGCs incubated in the presence of MG-132 and lactacystin were analyzed by SDS-PAGE, electroblotted, and probed with the anti-tau antibody, mAb Tau-1. As shown in Figure $3 B$ we found that the $17 \mathrm{kDa}$ band, corresponding to the major cleavage product of tau previously described, is not detectable in the presence of proteasome inhibitors. These findings suggest that these agents block proteasome function upstream the activation of proteases such as caspase- 3 and calpain, a conclusion also supported by the observation that the same inhibitors prevent the release of cytochrome c (A. Bobba, N. Canu, A. Atlante, E. Marra, and P. Calissano, unpublished observation), an event preceding caspase-3 activation in CGCs undergoing apoptosis (Bobba et al., 1999).

\section{Proteasome activity decreases during apoptosis}

The proteasome can cleave peptides on the carboxyl side of hydrophobic, basic, and acid residues (Orlowski, 1990). These proteolytic functions commonly referred to as the chymotryptic, tryptic, and postacidic or caspase-like, can be measured by evaluating the hydrolysis of the fluorogenic substrates Suc-LLVYMCA, Boc-LRR-MCA, and Z-LLE- $\beta$ Nap, respectively. We therefore determined whether and which of these specific activities are modulated during neuronal apoptosis. To this aim, control cells and cells undergoing apoptosis were homogenized in a buffer containing $5 \mathrm{~mm} \mathrm{ATP}$ and $20 \%$ glycerol to preserve the integrity of the $26 \mathrm{~S}$ proteasome (Hough et al., 1987), and their supernatant fractions were tested for the ability to hydrolyze these fluorogenic substrates. Assays were performed in a buffer ( $\mathrm{pH}$ 8.0) containing $5 \mathrm{~mm}$ EGTA to inhibit lysosomal peptidases and calpains. As shown in Figure $4 A$, the supernatant fractions of CGCs undergoing apoptosis exhibit a progressively reduced hydrolysis of Suc-LLVY-MCA to $\sim 60 \%$ of control value at $12 \mathrm{hr}$ of apoptosis. The time course analysis of this activity demonstrates that this decline parallels the number of apoptotic nuclei (Fig. $4 D$ ). A similar trend was also observed for trypsin-like and caspase-like activities of proteasome as detected using the fluorogenic substrates Boc-LRR-MCA and Z-LLE- $\beta$ Nap respectively (Fig. $4 B, C$ ), although the decline of caspase like-activity is less pronounced and does not mirror the extent of apoptosis. It is
(A)

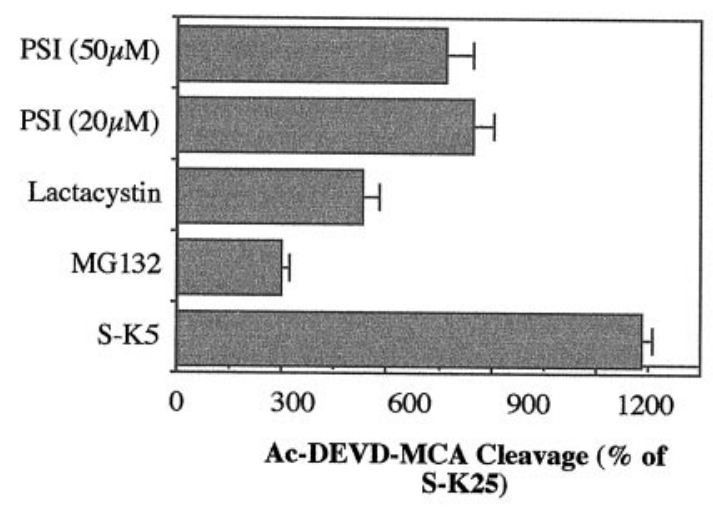

1500

(B)

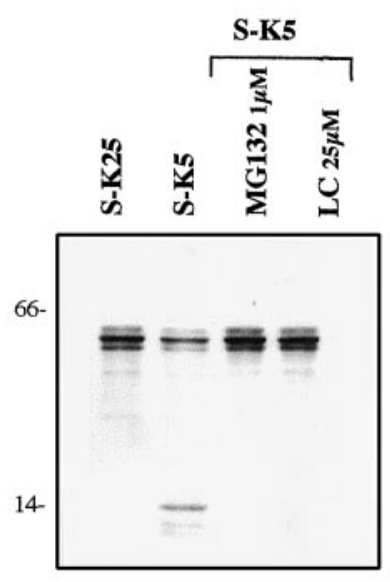

Figure 3. Inhibitors of the proteasomes block caspase activity and prevent cleavage of tau. $A$, Cultures were switched to $\mathrm{S}-\mathrm{K} 5$ medium in the absence or in the presence of proteasome inhibitors MG132 $(5 \mu \mathrm{M})$, Lactacystin $(25 \mu \mathrm{M})$, or PSI $(20$ or $50 \mu \mathrm{M})$. Control cultures were switched to S-K25. After $12 \mathrm{hr}$, cultures were lysed and assayed for DEVD-MCA cleavage. Accumulation of MCA was assayed fluorometrically after 20 min at room temperature. Data are reported as the percentage of the rate of cleavage in S-K25 extracts $(100 \%)$. B, Tau cleavage was analyzed by immunoblotting of cell extracts $12 \mathrm{hr}$ after induction of apoptosis triggered in the absence or in the presence of $1 \mu \mathrm{M}$ MG132 or $25 \mu \mathrm{M}$ Lactacystin $(L C)$. The mouse monoclonal antibody Tau-1 was used to detect tau cleavage (Canu et al., 1998).

interesting to note, moreover, that the time course analysis of the three distinct peptidase activities of proteasome revealed, in the early phase of apoptosis, a slight, but consistent increase compared to control cells (Fig. 4A-C).

To ascertain if the decline in proteasome activity was attributable to a decrease in the actual proteasomes content, equal amounts of proteins from control cells and cells undergoing apoptosis for different times were subjected to SDS-PAGE, electroblotted, and probed with a monoclonal antibody directed against all $\alpha$-proteasome subunits. As shown in Figure $4 E$, the intracellular level of proteasomes remained unchanged in apoptotic granule neurons as compared with control cells, indicating that the observed decline in proteasome activity during apoptosis is attributable to other causes (see Discussion). A similar result was also obtained using a mAb against the $\alpha$-subunit C9 (data not shown).

It has been reported that MG132, lactacystin, and PSI have 
(A)

(B)
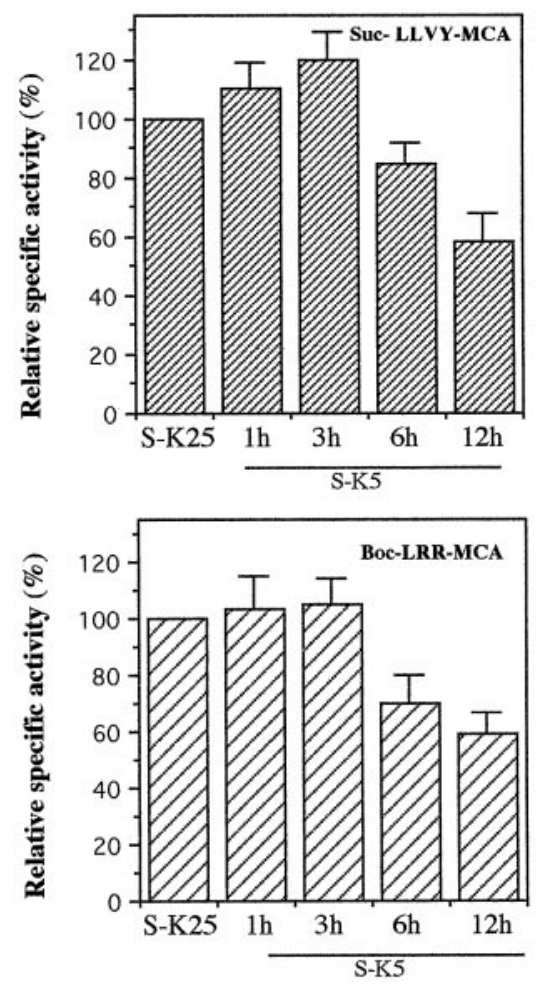

(C)

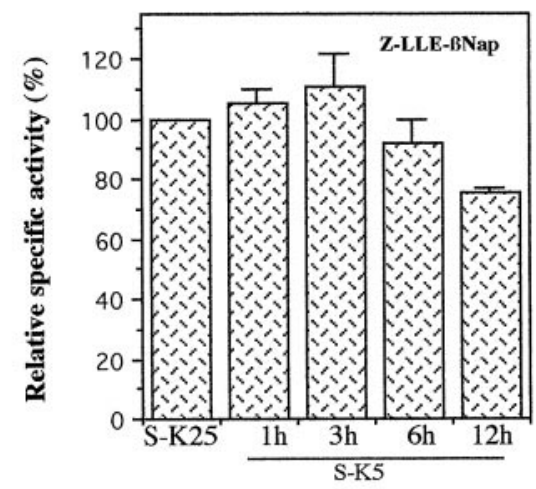

(D)

(E)

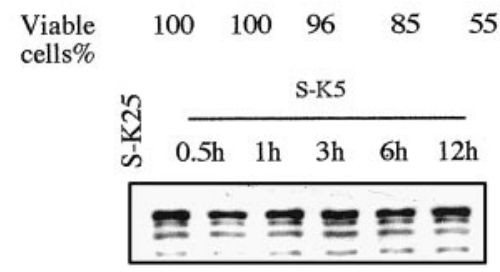

Figure 4. Profile of proteasome activities and proteasome concentration during the apoptosis of CGCs. A, Cultures at 6 DIV were washed and maintained in high-potassium and serum-free medium (S-K25) for $12 \mathrm{hr}$ or switched to K5 and serum free-medium (S-K5). At the time indicated after the induction of apoptosis, $10 \mu \mathrm{g}$ of supernatants were incubated with substrates specific for chymotrypsin-like (Suc-LLVY-MCA) $(A)$, trypsin-like (Boc-LRR-MCA) (B), and caspase-like (Z-LLE- $\beta$ Nap) activities $(C)$ at $37^{\circ} \mathrm{C}$ for 20,30 , and $60 \mathrm{~min}$, respectively, and assayed in triplicate. Specific activities are expressed as the percentage of activities of control cells, which have been given a value of 100 . Results are the mean \pm SD of experiments from three separate CGC preparations. $D$, For each time point the corresponding viability was determined, as described in Materials and Methods. E, Western blot analysis of proteasome content in $20 \mu \mathrm{g}$ of whole extracts, from control cells and cells undergoing apoptosis for different times, performed with a mAb against the $\alpha$-subunits of $20 \mathrm{~S}$ proteasome.

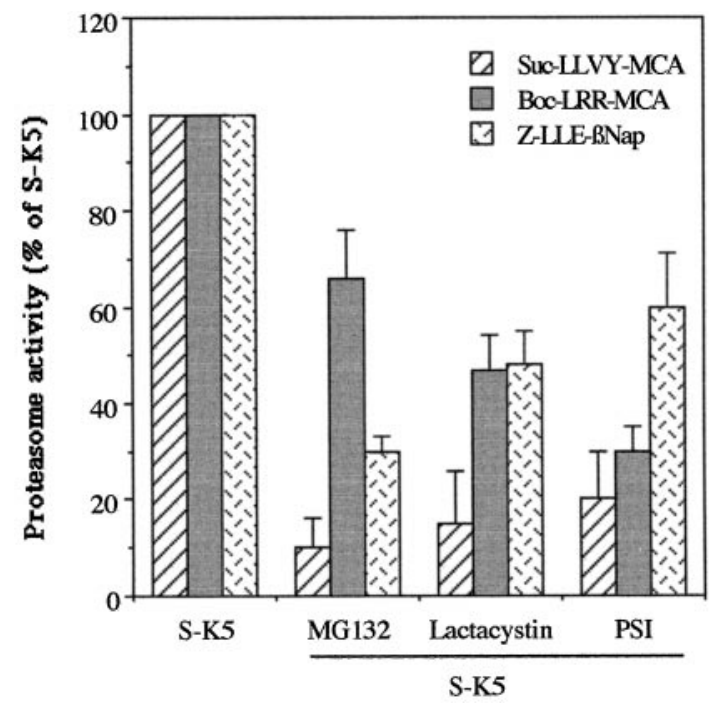

Figure 5. Effect of proteasome inhibitors on apoptosis-induced change in proteasome activity. Extracts of granule neurons deprived of $\mathrm{K}^{+}$and serum for $12 \mathrm{hr}$ in the absence or in the presence of proteasome inhibitors were incubated with substrates specific for the chymotrypsin, trypsin, and postacidic-like activities and assayed, as described in Materials and Methods. Data are expressed as the percentage of activities in S-K5. Results are the means $\pm \mathrm{SD}$ from two separate granule neurons preparations.

different inhibitory potencies on the proteasomal activities (for review, see Lee and Goldberg, 1998). Because they protect CGCs from apoptosis to a different extent (Fig. 1), we determined their effectiveness by incubating granule neurons in their presence and assessing the chymotrypsin, trypsin-like, and postacidic-like activities of proteasomes with specific substrates. As shown in Figure 5 all compounds inhibit the chymotrypsin-like activity to the same extent (MG132, $-90 \pm 6 \%$; PSI, $-80 \pm 10 \%$; lactacystin, $-85 \pm 10 \%)$. Considerable differences, on the contrary, were observed for trypsin-like activity $(-34 \pm 10 \%$ with MG132, $-50 \pm 5 \%$ with Lactacystin, and $-70 \pm 10 \%$ with PSI) as well as postacidic-like activity $(-65 \pm 5 \%$ with MG132, $-50 \pm 7 \%$ with Lactacystin, and $-38 \pm 11 \%$ with PSI). The data reported demonstrate that the inhibitors tested are able to enter the cells and to block the proteasome activity to an extent comparable to that previously reported for their antiapoptotic action. Moreover, on the basis of these results we hypothesize that the anti-apoptotic effect is exerted by inhibitors able to inhibit also the postacidiclike activity.

\section{Proteasome failure occurs downstream caspase activation}

To determine whether the reduced proteasome activity is a regulated event located downstream the caspase activation, we measured proteasome activities in supernatant fractions from CGCs induced to undergo apoptosis for $12 \mathrm{hr}$ in the presence or absence of the general caspase inhibitor Z-VAD-fmk $(100 \mu \mathrm{M})$. The hydrolysis of Suc-LLVY-MCA, Boc-LLR-MCA, and ZLLE $\beta$-Nap by CGCs was decreased to $53 \pm 8 \%, 58 \pm 11 \%$, and $73 \pm$ $4 \%$, respectively, after the apoptotic stimulus. When CGCs were induced in apoptosis in the presence of $100 \mu \mathrm{M}$ of Z-VAD-fmk, the chymotrypsin, trypsin, and caspase-like activities were partially restored mirroring the antiapoptic effect of this general caspase inhibitor in this model of neuronal apoptosis (Fig. 6). 


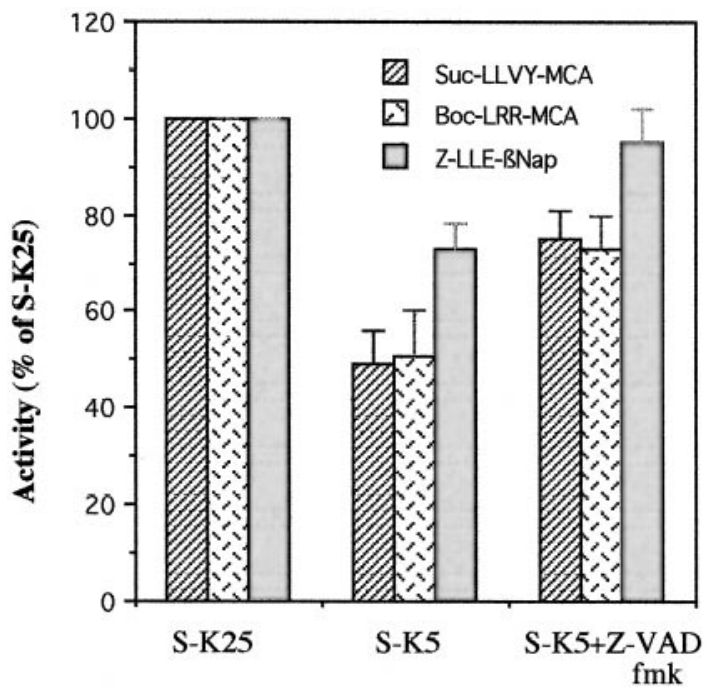

Figure 6. Effect of the general inhibitor, Z-VAD-fmk, on proteasome activities. CGCs were washed and maintained in high-potassium and serum-free medium (S-K25) for $12 \mathrm{hr}$ or switched to K5 and serum free-medium (S-K5) in the absence or in the presence of $100 \mu \mathrm{M} \mathrm{Z-VAD-}$ fmk. Twelve hours later, $10 \mu \mathrm{g}$ of supernatants were incubated with substrates specific for chymotrypsin-like (Suc-LLVY-MCA), trypsin-like (Boc-LRR-MCA), and caspase-like (Z-LLG- $\beta$ Nap) activities at $37^{\circ} \mathrm{C}$ for 20,30 , and $60 \mathrm{~min}$, respectively, and assayed in triplicate. Specific activities are expressed as the percentage of activities of control cells, where control cells have been given a value of 100 . Results are the mean \pm SD of experiments from three separate CGC preparations.

\section{Accumulation of ubiquitinated-proteins in cerebellar granule neurons undergoing apoptosis}

The progressive failure of proteasomal enzymatic activities prompted a study aimed at ascertaining whether induction of apoptosis was accompanied by changes in protein ubiquitination, as suggested by the marked reduction in the chymotrypsin-like activity of proteasomes. In fact, an impairment of this specific activity is closely related to the accumulation of ubiquitinated proteins (Heinemeyer et al., 1991; Figueiredo-Pereira et al., 1994).

We therefore examined the ubiquitin immunoreactivity using an antibody that is routinely used for immunohistochemical identification of ubiquitin-conjugated filamentous inclusions in neurodegenerating brains (Perry et al., 1987).

As shown in Figure $7 A$, neurons undergoing apoptosis and in the execution phase, recognizable as those having a small condensed or fragmented nucleus strongly stained by propidium iodide (Fig. $7 B$ ), are characterized by a prominent ubiquitin immunoreactivity in the cytoplasm (Fig. $7 A$ ) and in the degenerating neurites (Fig. $7 C$ ), whereas the nuclear staining is markedly reduced. In contrast, cells with a normal nuclear morphology exhibit a heterogeneous pattern of ubiquitin immunofluorescence barely detectable as a very faint staining of dendrites, perikarya, and nucleus.

We found that at any given time of apoptosis only a small fraction of the whole population of neurons identified by propidium staining demonstrate an high reactivity with the antibody recognizing ubiquitinated proteins. The simplest explanation is that such high positivity is transitory because of the subsequent loss of the cytoplasmatic content. In fact, cell ghosts that have lost membrane integrity are not stained with anti-ubiquitin antibody (Fig. $7 A, B$ ) suggesting that ubiquitinated proteins, which accumu-
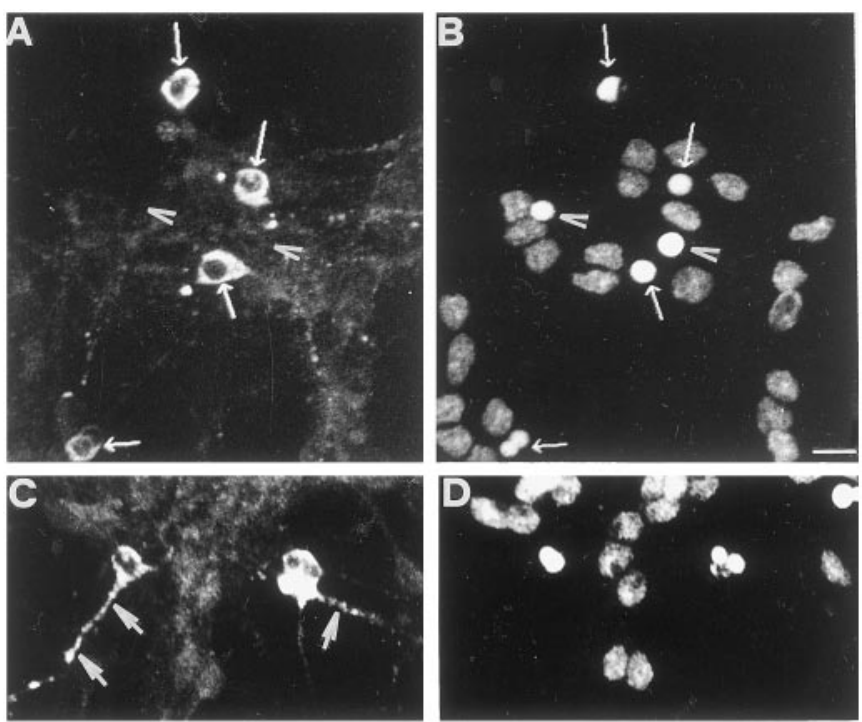

Figure 7. Ubiquitin immunostaining in cerebellar granule neurons undergoing apoptosis analyzed by confocal microscopy. Apoptosis in CGC was induced by potassium and serum withdrawal, as described in Materials and Methods. Double immunostaining of ubiquitin $(A, C)$ and DNA $(B, D)$ in CGCs was performed $6 \mathrm{hr}$ after induction, using a polyclonal anti-ubiquitin antibody and propidium iodide, as described in Materials and Methods. Notice that only few, scattered neurons are heavily stained $(A)$ compared to the number of neurons present in the same field $(B)$ and already stained with propidium. Arrows indicate the immunostaining with anti-ubiquitin $(A)$ and their corresponding nuclei $(B)$. Arrowheads indicate ghost cells that have lost the cytoplasm content $(C)$ and their corresponding nuclei $(D)$. Large arrows indicate beaded neurites stained very brightly for ubiquitin $(C)$. Scale bar, $7 \mu \mathrm{m}$.

late in the cytoplasm of dying cells, are subsequently sequestered in the apoptotic blebs.

We next assessed whether such increased and modified intracellular distribution was also accompanied by an altered cellular amount of polyubiquitinated proteins. Western blot analysis of cytoplasmatic and nuclear extracts derived from control cells and cells undergoing apoptosis were immunodeveloped with the same anti-ubiquitin antibody used for the immunofluorescence analysis. Figure $8 A$ shows that within $6 \mathrm{hr}$ after the apoptotic stimulus, a progressive increase of a heterogeneous population of high molecular weight proteins is detectable in the cytoplasmic extracts. Notice that at $12 \mathrm{hr}$ after the onset of apoptosis, whereas the extent of dying neurons continues to increase and approximates $50 \%$ of total neurons, the amount of ubiquitinated polypeptides is lower than that detectable at $6 \mathrm{hr}$, probably because of the sequestration of proteasome and ubiquitinated proteins in the apoptotic blebs as previously described (Pitzer et al., 1996). A different trend is observed for nuclear proteins, because during the same period a progressive reduction in the ubiquitin immunostaining occurs. It is interesting to note that the actual increase of ubiquitinated polypeptides is a measure of the whole population of dying neurons. Because, as shown in Figure 7, only a small fraction of the total population of apoptotic neurons exhibit a clear cut increase in ubiquitin immunostaining at any given time after the apoptotic stimulus, we are brought to conclude that in these neurons the increase of ubiquitinated proteins is several fold higher than that detected by Western blot. Furthermore, ubiquitinated proteins accumulate within $1 \mathrm{hr}$, despite the slight increase of chymotrypsin-like activity (Figs. $4 A$, $8 A$ ). This apparent discrepancy could be attributable to (1) the 
(A)

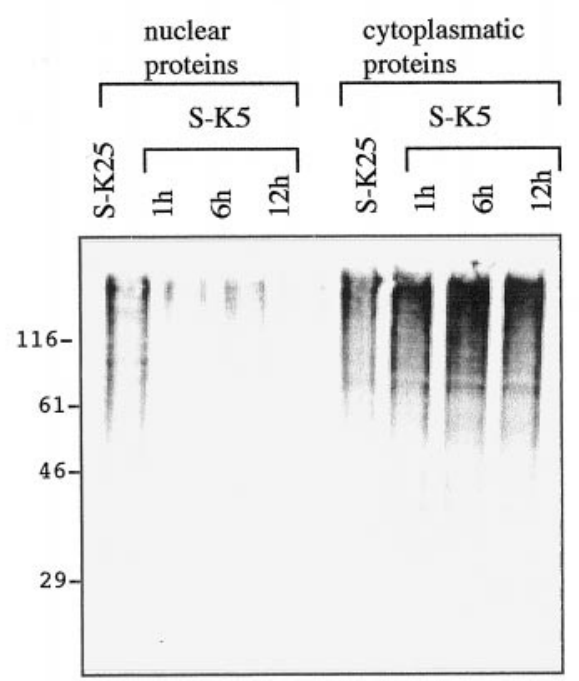

(B)

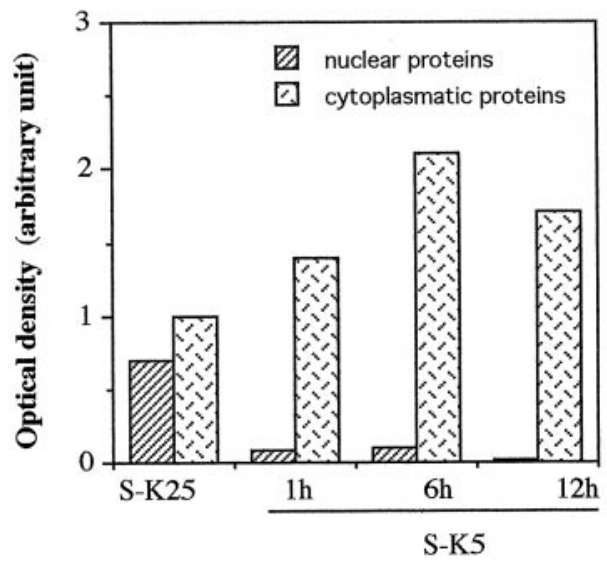

(C)

\begin{tabular}{|lllll|}
\hline $\begin{array}{l}\text { Viable cells } \\
\%\end{array}$ & 100 & $97 \pm 5$ & $89 \pm 10$ & $55 \pm 7$ \\
\hline
\end{tabular}

Figure 8. Accumulation of ubiquitin conjugates in cerebellar granule cells undergoing apoptosis. $A$, At 6 DIV cells were induced to apoptosis and after 1,6 , and $12 \mathrm{hr}$, nuclear $(10 \mu \mathrm{g})$ and cytoplasmatic proteins $(20$ $\mu \mathrm{g})$ were collected, resolved by SDS gel electrophoresis (8-15\%), and immunoblotted with the polyclonal anti-ubiquitin antibody, as described in Materials and Methods. Molecular weight markers are indicated on the left. B, Densitometric analysis of Western blot reported above. The absolute scanning values are given as arbitrary units. $C$, Time course of neuronal death after onset of apoptosis in sister cultures.

generation of proteins unable to enter the proteosome cavity because not properly ubiquitinated or edited, (2) the increased amount of ubiquitinated proteins not completely degraded by the slight increment of chymotrypsin activity shown in Figure 4; and (3) the existence of two populations of CGCs, one undergoing fast and another undergoing slow apoptotic death. (Miller and Johnson, 1996).

\section{Proteasome and caspase inhibitors prevent the intracytoplasmatic accumulation of ubiquitinated proteins in apoptotic neurons}

Because proteasome inhibitors counteract apoptosis of CGCs, we examined their influence on the intracytoplasmatic accumulation
S-K25

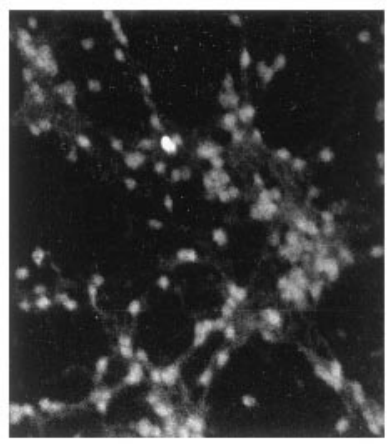

S-K5 + MG132

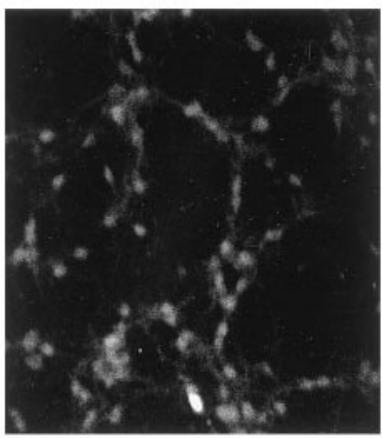

S-K5 + ALLM

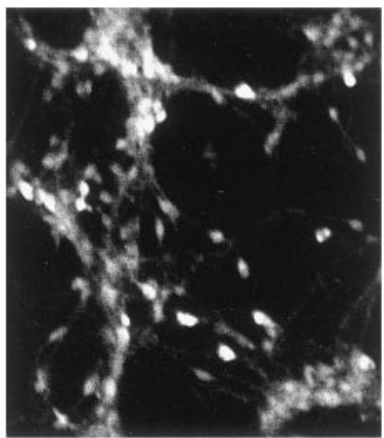

S-K5

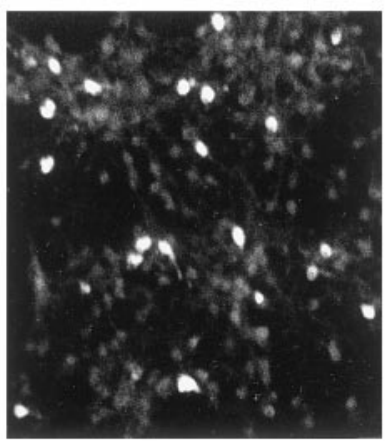

S-K5 + ZVAD-fmk

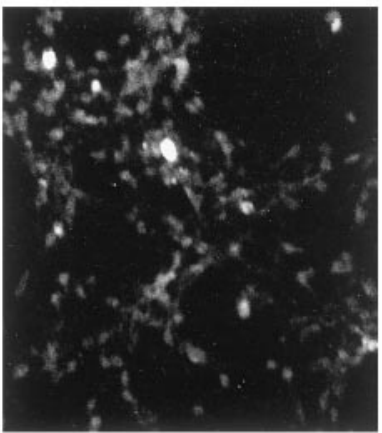

S-K5 + E64d

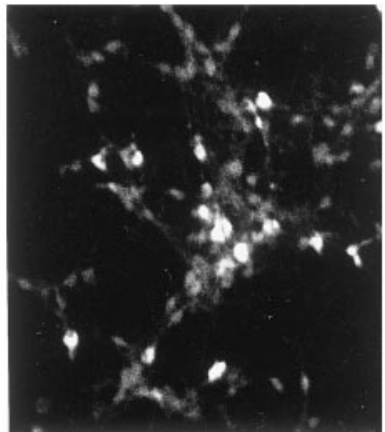

Figure 9. Proteasome and caspase inhibitors affect the intracytoplasmatic accumulation of ubiquitinated proteins in apoptotic granules. Apoptosis in CGCs was induced in the absence or in the presence of MG132 $(5 \mu \mathrm{M})$, Z-VAD-fmk $(100 \mu \mathrm{M})$, ALLM $(40 \mu \mathrm{M})$, and E64d $(20 \mu \mathrm{M})$. Ubiquitin immunostainings were examined $6 \mathrm{hr}$ after induction using anti-ubiquitin antibodies, as described in Materials and Methods. Fluorescent images were taken in a laser confocal microscope (Leica TCS 4D system, equipped with $100 \times 1.3-0.6$ oil-immersion objective, optical section $1 \mu \mathrm{M})$. Optical sections were stereo-pair and three-dimensional reconstituted. A representative experiment (of 3 ) is shown.

of ubiquitinated proteins by indirect immunofluorescence analysis performed $6 \mathrm{hr}$ after onset of the apoptotic stimulus. As can been seen in Figure 9 the proteasome inhibitor MG132 prevents the diffuse intracytoplasmatic accumulation of ubiquitinated proteins, characteristic of apoptotic cells and shown also in Figure 7. Furthermore, the general caspase inhibitor Z-VAD-fmk, was also able to prevent this event, although to a slightly lower extent, indicating that the massive build up of ubiquitinated proteins in degenerating granule neurons is an event located downstream the caspase activation, as also suggested by the finding that the 
decline in chymotrypsin-like activity of proteasomes is restored in apoptotic granules treated with Z-VAD-fmk (Fig. 6). On the contrary, treatment with calpain inhibitors (such as E64d or ALLM) did not block the accumulation of ubiquitinated proteins or inhibit apoptosis (Fig. 1C).

\section{Deubiquitinating activities decline during apoptosis}

As a first attempt to investigate the possible cause or causes of proteasome failure during neuronal apoptosis we measured the activity of DUB. These enzymes, also referred to as ubiquitin C-terminal peptidases, catalyze the removal of ubiquitin from various cellular adducts, thus playing an important role in the editing of ubiquitination state of proteins and in the recycling of ubiquitin (Wilkinson, 1997). The recycling of free ubiquitin from poly-ubiquitin remnants is required for the continued action of the complete proteolytic system. In fact, polyUb chains, not properly disassembled, bind avidly to and inhibit the $26 \mathrm{~S}$ proteasome complex, presumably via competition with polyubiquitinated substrates (Hadari et al., 1992; Amerik et al., 1997). DUB enzymes are encoded by two gene families: the $\mathrm{UCH}$ family (ubiquitin C-terminal hydrolases, with molecular weight of $\sim 30$ $\mathrm{kDa}$, hydrolyzing small C-terminal derivatives) and UBP family (ubiquitin-specific processing proteases, with molecular weight of $\sim 110 \mathrm{kDa}$, hydrolyzing large derivatives of ubiquitin).

We measured both activities in cell extracts of CGCs undergoing apoptosis using as substrate multi-ubiquitin chains composed of a mixture of $(\mathrm{Ub})_{4},(\mathrm{Ub})_{3}$, and $(\mathrm{Ub})_{2}$ oligomers. Such oligomers are converted by the action of DUB enzymes into monomeric ubiquitin $\mathrm{UB}_{1}$ (Wilkinson et al., 1995). These multiubiquitin chains are suitable substrates for measuring the activity of UBP family of DUB enzymes (Wilkinson et al., 1995). Moreover, the oligomer (UB) $)_{2}$ is also a good substrate for the UCH-L1 (Larsen et al., 1998), which is one of the most abundant enzyme in the brain, comprising up to $2 \%$ of total brain proteins (Leroy et al., 1998).

The cleavage of these substrates was monitored by Western immunoblot using anti-ubiquitin antibody, as described in Materials and Methods. As shown in Figure $10 \mathrm{~A}$, a striking difference in cleavage rate was observed, this being markedly reduced after $12 \mathrm{hr}$ of apoptosis, as suggested by the finding that the immunoreactivity for $(\mathrm{Ub})_{4},(\mathrm{Ub})_{3}$, and $(\mathrm{Ub})_{2}$ oligomers is greater in CGCs undergoing apoptosis than in control cells, whereas the immunoreactivity for $(\mathrm{UB})_{1}$, the end product of DUB activity, is lower in apoptotic cells.

Notice also that the DUB activity is restored in granule neurons undergoing apoptosis in the presence of a general caspase inhibitor Z-VAD-fmk (Fig. 10B) This latter finding suggest that the impairment of deubiquitinating activity is an event that occurs downstream of caspase activation. Similar results were also obtained using as substrate fluorogenic substrate Z-RLRGGMCA (Stein et al., 1995; Dang et al., 1998), which is based on the $\mathrm{C}$ terminus of ubiquitin (data not shown). Further experiments are required to clarify, by the use of specific substrate, which family of DUB enzymes, UCH or UBP, is responsible for the decreased deubiquitinating activity detected in apoptotic neurons.

\section{DISCUSSION}

Two major findings reported in this paper deserve some comments and deal with the demonstration that specific inhibitors of proteasome activities administered at the time of triggering apoptosis largely prevent this otherwise irreversible program of cell
(A)
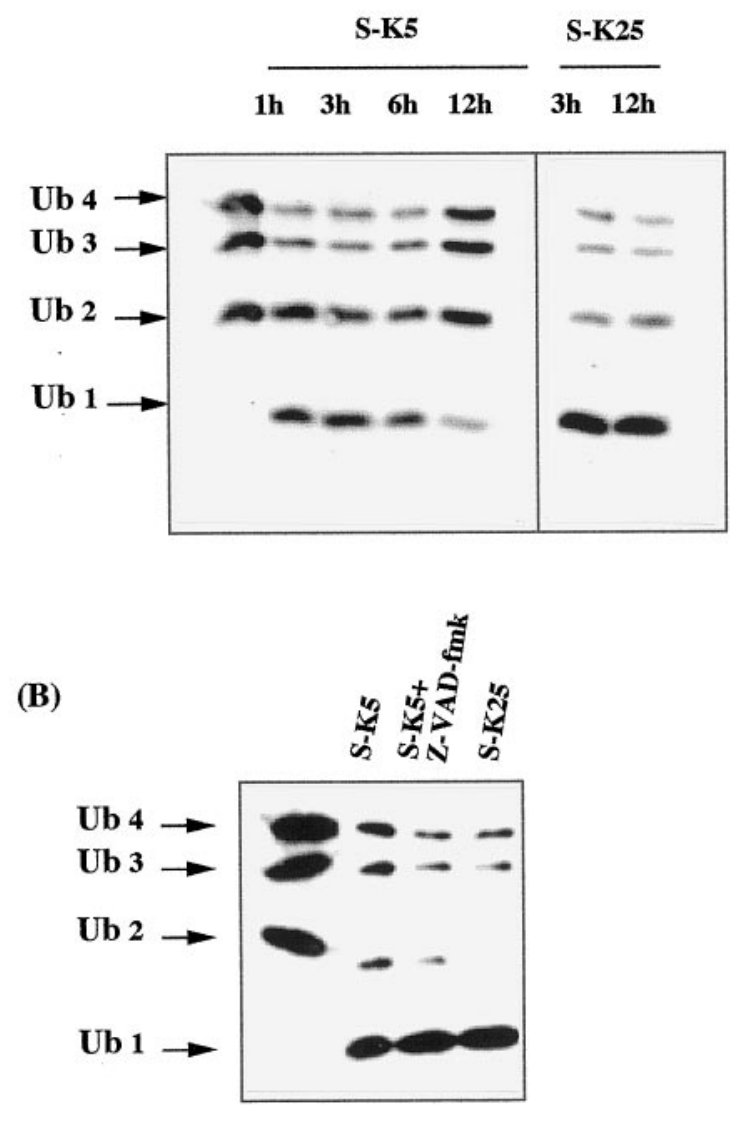

Figure 10. Deubiquitinating activity in granule neurons undergoing apoptosis. $A$, Cultures at 6 DIV were washed and switched to K5 and serum free-medium (S-K5) and in K25 and serum free-medium (S-K25) for 1, 3, 6 , and $12 \mathrm{hr}$. At the time indicated after the induction of apoptosis, $5 \mu \mathrm{g}$ of supernatants were incubated with $1 \mu \mathrm{g}$ of multi-ubiquitin chains, substrates for DUB enzymes, incubated at $22^{\circ} \mathrm{C}$ for $10 \mathrm{~min}$, and immunoblotted with anti-ubiquitin antibody. $B$, Effect of the general caspase inhibitor Z-VAD-fmk on deubiquitinating activities. CGCs were washed and maintained in high-potassium and serum free-medium (S-K25) for 12 $\mathrm{hr}$ or switched to $\mathrm{K} 5$ and serum free-medium (S-K5) in the absence or in the presence of $100 \mu \mathrm{M}$ Z-VAD-fmk. Twelve hours later deubiquitinating assay was performed as described above.

death, such inhibition being most probably upstream the caspase activation. The second peculiar finding is that within $12 \mathrm{hr}$ of inducing apoptosis, a progressive accumulation of ubiquitinated proteins occurs, likely as a result of a progressive deficit in proteasome chymotrypsin-like activity, such accumulation being downstream of the caspase activation. A corollary of these studies, in line with some previous hypothesis, postulates that such proteasome involvement may have some relevance with neurodegenerative diseases. For the sake of clarity, each of these specific issues will be separately discussed.

Previous studies have attributed to the proteasome a critical role in apoptosis triggered by different stimuli in terminally differentiated cells (Grimm et al., 1996; Sadoul et al., 1996). Our findings, using a panel of proteasomal inhibitors with different inhibitory capabilities against the proteasome, demonstrate that this proteolytic machinery plays also a role in death by apoptosis of CGCs. We have found that not all inhibitors exert the same protective effect. In fact, the most powerful blockers were MG132 and Lactacystin, producing a neuronal survival of 98 and $85 \%$, 
respectively, after $12 \mathrm{hr}$ of apoptosis. By contrast, another proteasome blocker PSI (Z-IE (OtBu) AL-CHO) is a poor inhibitor even at the highest concentration tested (50-100 $\mu \mathrm{M})$. Such weak inhibitory activity is in contrast with the report dealing with the protective effect of PSI (at concentration ranging from 10 to 100 nM) on sympathetic neurons deprived of NGF (Sadoul et al., 1996). The simplest explanation is that the composition of the proteasome complex in CGCs and sympathetic neurons is not identical, or that the pathway or pathways linking their function with other intracellular activities are distinct and they therefore exhibit markedly different sensitivity to this inhibitor. For example, proteasomes involved in antigen presentation differ both in composition and function from proteasomes involved in other processes (Driscoll et al., 1993). On the other side, it is possible that the block of cell death in CGCs requires the simultaneous repression of more than one peptidase activity of proteasome, one of which is of caspase-like nature. In fact, as shown in Figure 5 , the most powerful inhibitors are those that also affect more deeply the postacidic activity (MG132 and Lactacystin). This activity could be devoted to cleave a particular substrate that promotes cell death, for example a pro-caspase family member into an active form, or could degrade regulatory proteins that normally control the apoptotic pathway. This hypothesis is strengthened by the observation that proteasomes can cleave after Asp in synthetic peptide substrates (Rivett et al., 1994; Kisselev et al., 1999) and that proteasomes are the major ICE-like proteinase in P19 cells treated with retinoic acid (Kobayashi et al., 1996). On the basis of such considerations and of previous findings, it is tempting to place the proteasome activity in CGCs undergoing apoptosis upstream of the caspase activation, as already shown in sympathetic neurons deprived of NGF (Sadoul et al., 1996) and in thymocytes treated with dexamethasone, $\gamma$-irradiation, or etoposide (Grimm et al., 1996; Hirsch et al., 1998; Stefanelli et al., 1998). The suggestion that the proteasome complex is acting upstream of the caspases is also based on the finding that the proteasomal inhibitors block caspase- 3 activity and prevent the cleavage of tau in granule neurons undergoing apoptosis (Fig. 3). Furthermore, these inhibitors block the early release of cytochrome $\mathrm{c}$ from mitochondria (Bobba, Canu, Atlante, Marra, and Calissano, unpublished observations), an event preceding caspase-3 activation (Bobba et al., 1999).

After such early involvement, proteasomes become part of a generalized cellular failure that affects the major activities of the apoptotic neuron, as shown by the finding that CGCs undergoing apoptosis accumulate ubiquitinated-proteins (Figs. 7, 8A). Although several mechanisms could account for the building up of ubiquitinated proteins, a decrease of proteasome activity in CGCs undergoing apoptosis could be one of the major causes. We found that after $6 \mathrm{hr}$ of apoptosis there is a significant decline in proteasome activity that further decreases by $12 \mathrm{hr}$ and that it tightly reflects the extent of apoptosis. This decline involves the chymotrypsin-like, trypsin-like and to, a lower extent, the caspaselike activity (Fig. $4 A-C$ ). Among them, the chymotrypsin-like activity has been directly linked to the degradation of ubiquitin conjugates. Defects in the yeast proteasome subunits bearing this catalytic activity result in decreased ability of cells to cope with stress conditions, cause accumulation of ubiquitin conjugates, and reduce protein degradation rates (Heinemeyer et al., 1991). Moreover, the inhibition of chymotrypsin-like activity (by the inhibitor PSI) of proteasome in neuronal cells is sufficient to induce accumulation of ubiquitinated proteins (Figueiredo- Pereira et al., 1994), and a decrease of the proteasome chymotrypsin-like activ- ity is observed in transient ischemia (Kamikubo and Hayashi, 1996). Although a decline in proteasome function seems to play a major role, the possibility that during apoptosis the proteolytic machinery may be overwhelmed or incapable of dealing with an increased amount of ubiquitinated proteins cannot be ruled out. It is also possible that the proteasome efficacy is additionally hampered by the generation, during apoptosis, of poor substrates for proteolysis such as cross-linked or aggregated proteins because, for example, of the disruption of the intracellular sulfhydryl homeostasis (Figueiredo-Pereira et al., 1998).

The significant decrease in proteasome function is likely attributable to a specific downregulation and not of proteasome content, as suggested by the finding that the amount of proteasome subunits does not change within the first $24 \mathrm{hr}$ of apoptosis. Because we have used a broad range antiserum directed against all $\alpha$-subunits, we cannot exclude that a specific subunit could be a target of caspases, resulting in reduced activity. Whatever the correct explanation, the impairment in proteasome function is likely correlated and linked to the decline in deubiquitinating activities that also occurs downstream of the caspase activation. It is worth noting that deubiquitinating enzymes facilitate the protein degradation by the proteasome, possibly by supervising the ubiquitinated state of proteins and by preventing accumulation of ubiquitin chains generated as intermediates in substrate degradation (Hadari et al., 1992). These chains may need to be disassembled to avoid accumulation to a level that inhibit proteolysis. Disruption of DUB enzymes in yeast leads to a decrease in protein degradation, accumulation of polyubiquitin proteins, and to depletion of cellular ubiquitin pools (Papa and Hochstrasser, 1993; Amerik et al., 1997). Our finding that DUB activity declines downstream of caspase activation suggests that it could be directly or indirectly a target of caspase or caspases. In this regard, it must pointed out that a missense mutation in Parkinson's disease (Leroy et al., 1998) or intragenic deletion in gad mice (Saigoh et al., 1999) of the deubiquitinating enzyme UCH-L1 cause partial loss of the catalytic activity of this enzyme, which could lead to aberration in the proteolytic pathway and aggregation of proteins.

Our data provide evidence that apoptosis in neuronal cells is accompanied by an early involvement of proteasome activities followed by a decrease in its function. To date, two other studies reported the modifications of proteasome activity during dexamethasone-induced apoptosis in thymocytes (Beyette et al., 1998; Hirsch et al., 1998). Beyette et al., (1998) found that dexamethasone-induced apoptosis in rat thymocytes is accompanied by a reduction of proteasome activity similar to the extent of apoptosis. Hirsch et al. (1998), on the other hand, reported that, in the same experimental paradigm, the proteasome is activated concurrently with the onset of apoptotic death. Our data mirror partly those of Beyette et al. (1998), showing a decrease, during apoptosis, after a brief and slight increase, of all the activities of proteasome. In addition, our studies, using as a parameter of proteasome failure the accumulation of ubiquitinated proteins, place the decline of proteasome activity downstream of the caspase activation as also confirmed by the finding that the chymotrypsin-like activity is restored in supernatant fraction from CGCs induced to undergo apoptosis in the presence of Z-VAD-fmk.

It is reported that the high levels of ubiquitin immunoreactivity associated with the inclusion bodies characteristic of a range of neurodegenerative disorders is attributable to the inability of the intracellular proteolytic system in lysing these structures. Moreover, inappropriate apoptosis is believed to be the underlying 
mechanism in the pathogenesis of neurodegenerative diseases. The studies reported in this article define an important role of apoptosis for proteasome activity failure, likely caused by a deficit in deubiquitinating activities, in the accumulation of ubiquitinated proteins, giving new insights into the mechanism that generates ubiquitinylated inclusions in many neuropathologies .

The question then arises as to the nature of the mechanism that first involves proteasomes as primary actors of apoptosis, to the extent that their inhibition blocks this event, and subsequently, when their apoptosis-promoting activity has been launched to other intracellular site or sites, these same structures become object of their own message so that their most typical and preferred substrate, ubiquitinated proteins, accumulate in the cytoplasm of dying cells.

\section{REFERENCES}

Amerik AYu, Swaminathan S, Krantz BA, Wilkinson KD, Hochstrasser M (1997) In vivo disassembly of free polyubiquitin chains by yeast Ubp14 modulates rates of protein degradation by the proteasome. EMBO J 16:4826-38.

Armstrong RC, Aja TJ, Hoang KD, Gaur S, Bai X, Alnemri ES, Litwack G, Karanewsky DS, Fritz LC, Tomaselli KJ (1997) Activation of the CED3/ICE-related protease CPP32 in cerebellar granule neurons undergoing apoptosis but not necrosis. J Neurosci 15:553-562.

Beyette J, Mason GG, Murray RZ, Cohen GM, Rivett AJ (1998) Proteasome activities decrease during dexamethasone-induced apoptosis of thymocytes. Biochem J 332:315-320.

Bobba A, Atlante A, Sgaramella G, Calissano P, Marra E (1999) Early release and subsequent caspase-mediated degradation of cytochrome $\mathrm{C}$ in apoptotic cerebellar granule cells. FEBS Lett 457:126-130.

Canu N, Dus L, Barbato C, Ciotti MT, Brancolini C, Rinaldi AM, Novak M, Cattaneo A, Bradbury A, Calissano P (1998) Tau cleavage and dephosphorylation in cerebellar granule neurons undergoing apoptosis. J Neurosci 18:7061-7074.

Ciechanover A (1994) The ubiquitin-proteasome proteolytic pathway. Cell 79:13-21.

Cohen GM (1997) Caspase: the executioners of apoptosis. Biochem J 326:1-16.

Dang LC, Melandri FD, Stein RL (1998) Kinetic and mechanistic studies on the hydrolysis of ubiquitin C-terminal 7-amido-4-methylcoumarin by deubiquitinating enzymes. Biochemistry 37:1868-1879.

DiFiglia M, Sapp E, Chase KO, Davies SW, Bates GP, Vonsattel JP, Aronin N (1997) Aggregation of huntingtin in neuronal intranuclear inclusions and dystrophic neurites in brain. Science 277:1990-1993.

D'Mello SR, Galli C, Ciotti T, Calissano P (1993) Induction of apoptosis in cerebellar granule neurons by low potassium: inhibition of death by insulin-like growth factor I and cAMP. Proc Natl Acad Sci USA 90:10989-10993

Drexler HC (1997) Activation of the cell death program by inhibition of proteasome function. Proc Natl Acad Sci USA 94:855-860.

Driscoll J, Brown MG, Finley D, Monaco JJ (1993) MHC-linked LMP gene products specifically alter peptidase activities of the proteasome. Nature 365:262-4.

Eldadah BA, Yakovlev AG, Faden AI (1997) The role of CED-3-related cysteine proteases in apoptosis of cerebellar granule cells. J Neurosci 17:6105-13.

Enari M, Talanian RV, Wong WW, Nagata S (1996) Sequential activation of ICE-like and CPP32-like proteases during Fas-mediated apoptosis. Nature 380:723-726.

Fenteany G, Standaert RF, Lane WS, Choi S, Corey EJ, Schreiber SL (1995) Inhibition of proteasome activities and subunit-specific aminoterminal threonine modification by lactacystin. Science 268:726-731.

Figueiredo-Pereira ME, Berg KA, Wilk S (1994) A new inhibitor of the chymotrypsin-like activity of the multicatalytic proteinase complex (20S proteasome) induces accumulation of ubiquitin-protein conjugates in a neuronal cell. J Neurochem 63:1578-1581.

Figueiredo-Pereira ME, Yakushin S, Cohen G (1998) Disruption of the intracellular sulfhydryl homeostasis by cadmium-induced oxidative stress leads to protein thiolation and ubiquitination in neuronal cells. J Biol Chem 273:12703-12709.

Galli C, Meucci O, Scorziello A, Werge TM, Calissano P, Schettini G (1995) Apoptosis in cerebellar granule cells is blocked by high $\mathrm{KCl}$, forskolin, and IGF-1 through distinct mechanisms of action: the involvement of intracellular calcium and RNA synthesis. J Neurosci 15:1172-1179.

Galli C, Piccini A, Ciotti MT, Castellani L, Calissano P, Zaccheo D, Tabaton M (1998) Increased amyloidogenic secretion in cerebellar granule cells undergoing apoptosis. Proc Natl Acad Sci USA 95:1247-1252.

Grimm LM, Goldberg AL, Poirier GG, Schwartz LM, Osborne BA (1996) Proteasomes play an essential role in thymocyte apoptosis. EMBO J 15:3835-3844.

Hadari T, Warms JV, Rose IA, Hershko A (1992) A ubiquitin C-terminal isopeptidase that acts on polyubiquitin chains. Role in protein degradation. J Biol Chem 267:719-727.

Heinemeyer W, Kleinschmidt JA, Saidowsky J, Escher C, Wolf DH (1991) Proteinase yscE, the yeast proteasome/multicatalyticmultifunctional proteinase: mutants unravel its function in stress induced proteolysis and uncover its necessity for cell survival. EMBO J 10:555-62.

Hirsch T, Dallaporta B, Zamzami N, Susin SA, Ravagnan L, Marzo I, Brenner C, Kroemer G (1998) Proteasome activation occurs at an early, premitochondrial step of thymocyte apoptosis. J Immunol 161:35-40.

Hochstrasser M (1995) Ubiquitin, proteasome, and the regulation of intracellular protein degradation. Curr Opin Cell Biol 7:215-233.

Hough R, Pratt G, Rechsteiner M (1987) Purification of two high molecular weight proteases from rabbit reticulocyte lysate. J Biol Chem 262:8303-8313.

Jentsch S (1992) The ubiquitin-conjugation system. Annu Rev Genet 26:179-207.

Kamikubo T, Hayashi T (1996) Changes in proteasome activity following transient ischemia. Neurochem Int 28:209-212.

Kisselev AF, Akopian TN, Woo KM, Goldberg AL (1999) The sizes of peptides generated from proteins by mammalian 26 and 20 S proteasomes. J Biol Chem 274:3363-3371.

Kobayashi T, Shinozaki A, Momoi T, Arahata K, Tsukahara T (1996) Identification of an interleukin-1 beta converting enzyme-like activity that increases upon treatment of P19 with retinoic acid as the proteasome. J Biochem 120:699-704.

Laemmli UK (1970) Cleavage of structural proteins during the assembly of the head of bacteriophage T4. Nature 227:680-685.

Larsen CN, Krantz BA, Wilkinson KD (1998) Substrate specificity of deubiquitinating enzymes: ubiquitin $\mathrm{C}$-terminal hydrolases. Biochemistry 37:3358-68.

Lee DH, Goldberg AL (1998) Proteasome inhibitors: valuable new tools for cell biologist. Trends Cell Biol 8:397-403.

Leroy E, Boyer R, Auburger G, Leube B, Ulm G, Mezey E, Harta G, Brownstein MJ, Jonnalagada S, Chernova T, Dehejia A, Lavedan C, Gasser T, Steinbach PJ, Wilkinson KD, Polymeropoulos MH (1998) The ubiquitin pathway in Parkinson's disease. Nature 395:451-452.

Levi G, Aloisi F, Ciotti M T, Gallo V (1984) Autoradiographic localization and depolarization-induced release of acidic amino acids differentiating cerebellar granule cells cultures. Brain Res 290:77-86.

Lowe J, Mayer RJ, Landon M (1993) Ubiquitin in neurodegenerative diseases. Brain Pathol 3:55-65.

Manthorpe M, Fagnani R, Skaper SD, Varon S (1986) An automated colorimetric microassay for neuronotrophic factors. Brain Res 390:191-198.

Marks N, Berg MJ, Guidotti A, Saito M (1998) Activation of caspase-3 and apoptosis in cerebellar granule cells. J Neurosci Res 52:334-341.

Miller TM, Johnson Jr EM (1996) Metabolic and genetic analyses of apoptosis in potassium/serum-deprived rat cerebellar granule cells. J Neurosci 16:7487-7495.

Morishima-Kawashima M, Hasegawa M, Takio K, Suzuki M, Titani K, Ihara Y (1993) Ubiquitin is conjugated with amino-terminally processed tau in paired helical filaments. Neuron 10:1151-1160.

Nardi N, Avidan G, Daily D, Zilkha-Falb R, Barzilai A (1997) Biochemical and temporal analysis of events associated with apoptosis induced by lowering the extracellular potassium concentration in mouse cerebellar granule neurons. J Neurochem 68:750-759.

Nath R, Raser KJ, Stafford D, Hajimohammadreza I, Posner A, Allen H, Talanian R, Yuen P, Gilbertsen RB, Wang KKW (1996) Nonerythroid $\alpha$-spectra breakdown by calpain and interleukin $1 \beta$ converting-enzyme-like protease(s) in apoptotic cell: contributory roles of both protease families in neuronal apoptosis. Biochem $\mathbf{J}$ 319:683-690. 
Orlowski M (1990) The multicatalytic proteinase complex, a major extralysosomal proteolytic system. Biochemistry 29:10289-10297.

Palombella VJ, Rando OJ, Goldberg AL, Maniatis T (1995) The ubiquitin-proteasome pathway is required for processing the NF-KB1 precursor protein and the activation of NF-KB. Cell 78:773-785.

Papa FR, Hochstrasser M (1993) The yeast DOA4 gene encodes a deubiquitinating enzyme related to a product of the human tre- 2 oncogene. Nature 366:313-319.

Perry G, Friedman R, Shaw G, Chau V (1987) Ubiquitin is detected in neurofibrillary tangles and senile plaque neurites of Alzheimer disease brains. Proc Natl Acad Sci USA 84:3033-3036.

Peters JM (1994) Proteasome:protein degradation machines of the cell. Trends Biochem Sci 19:377-382.

Pitzer F, Dantes A, Fuchs T, Baumeister W, Amsterdam A (1996) Removal of proteasomes from the nucleus and their accumulation in apoptotic blebs during programmed cell death. FEBS Lett 394:47-50.

Rivett AJ, Savory PJ, Djaballah H (1994) Multicatalytic endopeptidase complex: proteasome. Methods Enzymol 244:331-350.

Rock KL, Gramm C, Rothstein L, Clark K, Stein R, Dick L, Hwang D, Goldberg AL (1994) Inhibitors of the proteasome block the degradation of most cell proteins and the generation of peptides presented on MHC class I molecules. Cell 78:761-771.

Sadoul R, Fernandez PA, Quiquerez AL, Martinou I, Maki M, Schroter M, Becherer JD, Irmler M, Tschopp J, Martinou JC (1996) Involvement of the proteasome in the programmed cell death of NGFdeprived sympathetic neurons. EMBO J 15:3845-3852.

Saigoh K, Wang Y-L, Suh J-G, Yamanishi T, Sakai Y, Kiyosawa H, Harada T, Ichihara N, Wakana S, Kikuchi T, Wada K (1999) Intragenic deletion in gene encoding ubiquitin carboxy-terminal hydrolase in gad mice. Nat Genet 23:47-51.

Schagger H, von Jagow G (1987) Tricine-sodium dodecyl sulfatepolyacrylamide gel electrophoresis for the separation of proteins in the range from 1 to $100 \mathrm{kDa}$. Anal Biochem 166:368-379.

Schulz JB, Weller M, Klockgether T (1996) Potassium deprivationinduced apoptosis of cerebellar granule neurons: a sequential require- ment for new mRNAand protein synthesis, ICE-like protease activity, and reactive oxygen species. J Neurosci 16:4696-4706.

Smale G, Nichols NR, Brady DR, Finch CE, Horton WEJ (1995) Evidence for apoptotic cell death in Alzheimer's disease. Exp Neurol 133:225-230.

Soto AM, Sonnenschein C (1985) The role of estrogen on the proliferation of human breast tumor cells (MCF-7). J Steroid Biochem 23:87-94.

Stefanelli C, Bonavita F, Stanic I, Pignatti C, Farruggia G, Masotti L, Guarnieri C, Caldarera CM (1998) Inhibition of etoposide-induced apoptosis with peptidealdehyde inhibitors of proteasome. Biochem $\mathrm{J}$ 332:661-665.

Stein RL, Chen Z, Melandri F (1995) Kinetic studies of isopeptidase T: modulation of peptidase activity by ubiquitin. Biochemistry 34:12616-12623.

Steller H (1995) Mechanism and genes of cellular suicide. Science 267:1445-1449.

Su JH, Anderson AJ, Cummings BJ, Cotman CW (1994) Immunohistochemical evidence for apoptosis in Alzheimer's disease. NeuroReport 5:2529-2533.

Takeda A, Mallory M, Sundsmo M, Honer W, Hansen L, Masliah E (1998) Abnormal accumulation of NACP/alpha-synuclein in neurodegenerative disorders. Am J Pathol 152:367-372.

Thompson C (1995) Apoptosis in the pathogenesis and treatment of disease. Science 267:1456-1462.

Volontè C, Ciotti MT, Battistini L (1994) Development of a method for measuring cell number: application to CNS primary neuronal culture. Cytometry 17:274-276.

Wilkinson K (1997) Regulation of ubiquitin-dependent process by deubiquitinating enzymes. FASEB J 11:1245-1246.

Wilkinson KD, Tashayev VL, O'Connor LB, Larsen CN, Kasperek E, Pickart CM (1995) Metabolism of the polyubiquitin degradation signal: structure, mechanism, and role of isopeptidase T. Biochemistry 34:14535-14546. 